\title{
Universities should opt for teaching or research
}

In his anniversary address to the Royal Society last week, Lord Todd, the Society's President, lamented the deteriorating health of Britain's science and argued for a restructuring of the university system. Here we publish extracts from his speech.

THE rapid growth of the university system in the 1960s brought about a vast expansion in tenured staff usually by the recruitment of relatively young men and women taken from the normal supply of university graduates and not invariably of the highest quality. Many, if not most, of these remain today at the same institutions and are likely to do so for perhaps another two decades under the tenure system.

A detailed study of chemistry departments in British universities has been made by Professor Colin Eaborn who summarised his findings thus: "At present only $7.8 \%$ of the staff of chemistry departments are below 35 years of age; the proportion will probably fall to about $4 \%$ in five years' time and rise to only about $9 \%$ in ten years time. The proportion below 40 years of age, now $26 \%$ will fall to about $12.5 \%$ in five years and to about $10 \%$ in ten years time. During those ten years the proportion of staff over 50 will rise from the present $28 \%$ to about $62 \%$."

Viewing Europe as a whole, the European Science Foundation suggests that the chance for a junior research assistant to reach a permanent university appointment has gone down from about $70 \%$ during the 1960 s to about $15 \%$ in this decade. The outlook is indeed bleak. Surprising though it may seem, the academic research profession has within a few years been transformed from one of the most mobile to one of the most static. This is particularly so in the United Kingdom, where the economic stagnation of recent years has all but staunched the flow of academics in mid-career into other occupations. Many young scientists are seeking to retain their present precarious positions by hand-to-mouth grants because they fear that a change to another university or research institute might jeopardize their chance of obtaining a permanent appointment.

Several awkward, even painful, questions arise. Is it, for example, to continue to be taken as an article of faith that all established academics are capable of first-class research and that all students obtaining first-or upper-second-class honours degrees should be encouraged and provided with the wherewithal to pursue academic research? The answer to both questions must, I fear, be no. If we continue to believe that each department in every one of our present universities should have a substantial research school the strain on our financial resources may

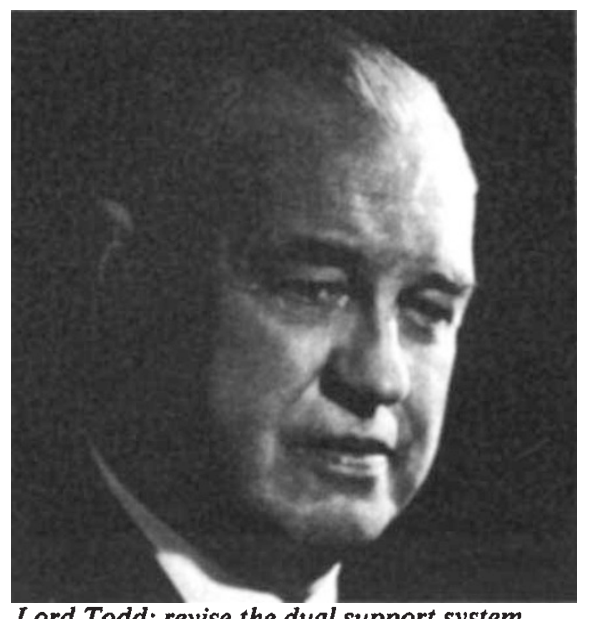

Lord Todd: revise the dual support system

become intolerable.

The dual support system of the University Grants Committee and the Research Councils would ideally ensure that extra funds for the support of research were concentrated on those most likely to spend them well; as things now stand, however, while there is no reason to believe that really able young scientists with good projects to put forward will be denied temporary funding to initiate them, the prospects of their being given a sufficient measure of permanence to build up a centre of excellence in their institution is small.

It is not possible - and it may not even be desirable - that all departments of, say, chemistry or physiology should stand out for the high quality of their research. Some, for example, have too small a staff adequately to sustain undergraduate teaching and to supervise at the same time programmes of post-graduate work which all departments in all disciplines appear to regard as the essential breath of life. Need this requirement for large postgraduate programmes be universal?

It is a remarkable fact that in proportion to population there are more institutions awarding PhDs in physics in the UK than in the US. In the US we find many more institutions devoted to professional education and applied sciences and there are many distinguished universities whose reputation rests substantially on the quality of their basic teaching. Such diversity in our institutions should be encouraged. Why should there not be some differentiation between those who teach and those who pursue research?

Unfortunately the present machinery for the support of higher education and research in the United Kingdom was not devised for the encouragement of diversity. For all its undoubted virtues the University Grants Committee system does require that universities should compete within what is increasingly a common framework of objectives. So competition between them is almost always on familiar terms.

Preliminary (and anecdotal) evidence suggests that in this competition Oxbridge and the older civic universities are winning out. If this be the case and the trend continues then we will end up with a hierarchy in which the universities lower in the pecking order will be trying to do the same things as the others but doing them with students who are not suited to them and would do better and become more useful citizens with a more vocational type of education.

If we are to change our present university pattern, the mechanisms by which we support research in academic institutions may also have to undergo some changes. Project grant applications will no longer be assessed simply on their merits alone without reference to the circumstances under which the research is to be carried out. Research projects in a given field will tend to be concentrated in one, or in only a very few, centres with considerably larger research groups than are usual today. It may well become necessary for the research councils to be more selective in the way in which postgraduate studentships are allocated to university departments; more radically, they may even have to think of making the grants to students of exceptional promise rather than to their potential supervisors. Another convention that may have to go is that every reasonably able $\mathrm{PhD}$ graduate can expect as of right to have two or three years of postdoctoral research during which he can establish a claim on a tenured research post.

The frequent frustration of this expectation is one of the saddest of the current symptoms of malaise in our university research. But the vigour of our research enterprise would surely suffer if all those concerned were now provided with a formal tenured career structure as many of them are now asking despite the current staff structure in our universities.

Unfortunately there is no quick or easy answer. A reduction in the university retiring age to 60 without any reduction in pension would undoubtedly speed up return to a normal age distribution, but would be expensive. Encouragement of voluntary retirement at 55 with generous financial compensation has also been suggested but would probably not be welcomed by more than a few individuals, and would also be costly.

If we accept that some universities will be much more devoted to vocational teaching and less to research than others, then only in a proportion of our universities need the situation be treated as urgent. These urgent cases could have a retiring age of 60 (with full pension) introduced if only temporarily so that a more normal flow of young academics could be reintroduced. I believe the overall cost would be tolerable.

osee page 552 for the legal position on short term contracts in the UK 